\title{
SMARTPHONE, QR CODE GENERATOR E GOOGLE FORMS NA ENSINAGEM DO TRONCO ENCEFÁLICO EM NEUROANATOMIA
}

\author{
Luciana Maria de Morais Martins Soares ${ }^{1}$ \\ Rodrigo Farias Herculano Mendes ${ }^{2}$
}

\section{RESUMO}

O objetivo deste trabalho é apresentar o relato da experiência do uso do smartphone, do $Q R$ code generator e do Google Forms no favorecimento do ensino do tronco encefálico em Neuroanatomia. Para efetivação da proposta foram seguidos os seguintes passos: seleção das imagens neuroanatômicas; edição dessas imagens de modo a sinalizar a estrutura que se desejava identificar; criação do Google Forms utilizando as imagens e a tarefa de múltipla escolha; criação e acesso ao $Q R$ code e disponibilização aos aprendentes para execução junto ao celular. Após aula expositivo-dialogada sobre tronco encefálico com auxílio de projetor multimídia, foi apresentado $O Q R$ code com a tarefa de revisão. Após o preenchimento e o envio da tarefa, geraram-se, em Excel, gráficos contendo a frequência das respostas para análise e discussão dos itens que apresentaram maior número de equívocos. As tecnologias simplificam o processo de avaliação discente e oferecem um ensino mais atrativo, moderno e dinâmico.

Palavras-chave: Tecnologias do ensino. Neuroanatomia. Smartphone. $Q R$ code.

\section{Como citar este documento - ABNT}

SOARES, Luciana Maria de Morais Martins; MENDES, Rodrigo Farias Herculano. Smartphone, $Q R$ code generator e Google Forms na ensinagem do tronco encefálico em Neuroanatomia. Revista Docência do Ensino Superior, Belo Horizonte, v. 9, e012059, p. 1-17, 2019. DOI: https://doi.org/10.35699/22375864.2019.12059.

Recebido em: 22/02/2019 Aprovado em: $21 / 05 / 2019$ Publicado em: 10/10/2019

\footnotetext{
${ }^{1}$ Centro Universitário de João Pessoa (UNIPÊ), João Pessoa, PB, Brasil. ORCID ID: https://orcid.org/0000-0002-6559-9558. E-mail: luciana_momaso@hotmail.com.

${ }^{2}$ Centro Educacional de Ensino Superior de Patos (CEPESP), Patos, PB, Brasil. ORCID ID: https://orcid.org/0000-0003-3167-0018. E-mail: rodrigofhmendes@gmail.com.
} 


\section{TELÉFONO INTELIGENTE, QR CODE GENERATOR Y GOOGLE FORMS EN LA ENSEÑANZA DEL TRONCO ENCEFÁLICO EN NEUROANATOMIA}

\section{RESUMEN}

El objetivo de este trabajo es presentar el relato de experiencia del uso del teléfono inteligente, del $Q R$ code generator y del Google Forms en el fomento de la enseñanza del tronco encefálico en la Neuroanatomía. Para la aplicación de la propuesta se siguieron los siguientes pasos: selección de las imágenes neuroanatómicas; edición de estas imágenes para señalar la estructura que se deseaba identificar; creación del Google Forms utilizando las imágenes y la tarea de selección múltiple; creación y acceso al $Q R$ code y presentación a los estudiantes para ejecución junto al celular. Después de la clase expositivo-dialogada sobre tronco encefálico, con ayuda del proyector multimedia, se presentó el $Q R$ code con la tarea de revisión. En seguida, se generaron, en Excel, gráficos que contenían la frecuencia de las respuestas para el análisis y la discusión de los ítems que presentaron mayor número de equívocos. Las tecnologías simplifican el proceso de evaluación del estudiante y ofrecen una enseñanza más atractiva, moderna y dinámica.

Palabras clave: Tecnologías de ensenãnza. Neuroanatomía. Teléfono inteligente. QR code.

\section{SMARTPHONE, QR CODE GENERATOR AND GOOGLE FORMS IN THE TEACHING OF BRAINSTEM IN NEUROANATOMY}

\section{ABSTRACT}

The goal of this work is to present an experience report using smartphone, QR code generator and Google Forms in favor of the teaching of brainstem in Neuroanatomy. The proposal was implemented by the following steps: selection of neuroanatomical images; edition of the images in order to signal the structure to be identified; creation of Google Forms by the usage of images and by the multiple-choice task; access and creation of the QR code, and finally execution of the task by the learners with a cell phone. After an expositorydialogue class about the brainstem with the help of the multimedia projector, the QR code was presented with the task of revision. After completing and sending the task, we generated, on Excel, graphs containing the frequency of the answers for analysis and discussion of the items that presented the greatest number of misconceptions. Technologies simplify the student evaluation process and offer a more attractive, modern and dynamic teaching.

Keywords: Teaching technologies. Neuroanatomy. Smartphone. QR code. 


\section{INTRODUÇÃO}

A sala de aula consiste em um espaço de encontro e de desencontro. Por um lado, um encontro com o mundo dos saberes, das competências e das habilidades que precisam ser estimuladas e desenvolvidas. Por outro lado, o desencontro entre "o desejo curioso de conhecer e os formatos didáticos lineares e reguladores", que algumas vezes não estimulam o estudante a ser coautor da própria aprendizagem (NÖRNBERG; FORSTER, 2016, p. 188).

Essa mudança do perfil, cujo aprendizado colaborativo é pautado pelo desejo de aprender, refletir, perguntar, analisar, confrontar e descobrir, veio acompanhada de um contexto cada dia mais digital, no qual a particularidade mais notória é que quase tudo se relaciona com os avanços tecnológicos, tornando inevitável ignorar o uso de tecnologias no cotidiano do ambiente educacional universitário (RIBAS et al., 2017).

Com base em princípios teóricos e práticos da aprendizagem colaborativa, a educação aberta na era digital visa a propiciar que "coaprendizes desenvolvam todo seu potencial nos espaços digitais e híbridos, tornando-os seres humanos perfeitamente ajustados a sociedades [...]" (MOREIRA; MONTEIRO, 2015, p. 385).

Essa realidade implica uma alteração na forma de pensar e fazer a docência, de modo a corresponder às necessidades educacionais atuais. Assim, ferramentas distintas emergem dentro desse contexto, e cabe, ao docente e às instituições de ensino, a busca e a capacitação constante para acompanhar as constantes mudanças nesse cenário.

\section{O CENÁRIO DA ENSINAGEM NO ÂMBITO UNIVERSITÁRIO}

A concepção de sala de aula, ao longo dos anos, tem sido ressignificada para um espaço não absoluto de ensinar por ensinar. Identifica-se que se faz urgente prover competências (intencionalidade de) e habilidades (instrumentalização para) que possibilitem ao aprendente não somente a absorção bruta dos saberes, porém e sobretudo a compreensão dos fenômenos de maneira crítica, reflexiva e com reversão prática dos conteúdos abordados (NÖRNBERG; FORSTER, 2016).

Na perspectiva das autoras supracitadas, a sala de aula se torna um ambiente de "encontro, de criação e de recriação de aprendizagens", onde se pode ter e manter um diálogo no qual são preservados tanto a liberdade quanto a expressão, assim como o compromisso do ensinar e do aprender. Para tanto, é de suma importância que os atores principais desse enredo, ou seja, os docentes facilitadores e os discentes aprendentes, estejam abertos e dispostos a dialogar e que juntos possam construir um contrato de convivência para o mundo contemporâneo que requer também a internalização de valores de integração social e de libertação individual. 
Em particular, para o contexto universitário, a prática em sala de aula exige não somente os saberes do campo disciplinar, mas também, sobremaneira, os saberes pedagógicos que, articulados com os saberes da experiência profissional, concretizam o processo de ensinagem (ALTHAUS; BAGIO, 2017). Assim, o contexto atual é orientado pela centralidade do aprendente na construção de uma aprendizagem significativa, de forma a possibilitar que ele seja capaz de autoadministrar suas próprias metas e estratégias para obtenção da informação e dos resultados que espera adquirir, fazendo-o voluntariamente, de modo motivado, crítico e reflexivo (RODRÍGUEZ, 2014).

Nesse contexto, o professor universitário, ao fazer uma opção metodológica, precisa ter consciência de que há distintas concepções de conhecimento, que estão articuladas e presentes no desenvolvimento dos saberes acadêmicos (ALTHAUS; BAGIO, 2017). Assim, basicamente, o processo de ensinagem na universidade consiste em desenvolver no estudante uma série de competências para que possa sobressair-se em uma sociedade desafiante que lhe exige constantemente novos aprendizados (RODRÍGUEZ, 2014).

Quanto às ferramentas metodológicas para alcançar tal perfil, verifica-se a importância do bom aproveitamento do espaço-tempo como um traço importante da pedagogia universitária, que visa a priorizar o processo de construção do conhecimento tanto quanto o resultado obtido, além da participação discente mais ativa (ALTHAUS; BAGIO, 2017).

Identifica-se assim, que o paradigma educacional está modificando-se e tem caracterizadose como cooperativo, compartilhado, participativo, personalizado e autoiniciado. Essa roupagem exige maiores investimentos, principalmente quanto ao aspecto tecnológico, na intenção de garantir a adequação da abordagem em sala de aula com o perfil discente atual (JO et al., 2014).

Verifica-se, então, que o cenário precisa ser modificado pela inclusão de novas estratégias educacionais, pela mudança do perfil do professor e também pelas novas gerações em ascensão tanto em instituições de ensino como no mercado de trabalho. Dessa forma, essas estratégias funcionarão como facilitadoras do processo, apontando, dentro do ambiente de aprendizagem, os caminhos a ser percorridos a fim de desenvolver as competências específicas de cada curso de graduação (HASHIMOTO; CIACCIO; GUERRA, 2018).

Por inovação educacional, Nardi, Bastos e Terrazzan (2008) apud Cortela (2016) ressaltam que nem sempre o que é considerado como novo para um sujeito é novo em relação ao que já existe. Assim, expressam que, para ser inovadora, a ideia ou a forma como ela é posta em prática deve ser original. Além disso, é possível que ela represente um processo incomum, que demande tempo de vigência e/ou incorporação de novas práticas assim como planejamento de ações e/ou materiais com embasamento teórico. Ao final, os efeitos da 
inovação representam melhoria ou aperfeiçoamento do que já se tem em sala de aula, seja para quem a propõe, seja para quem a põe em prática, ou para quem ela atende.

Percebe-se assim, uma tendência contemporânea a contrapor-se ao nomeado "modelo bancário" de aprendizagem, centrado no docente, que é detentor único do saber e que o apresenta ao "aluno" mediante explanações expositivas, visando à retenção de conhecimento para aplicação em uma prova. Em contrapartida, fortalece-se cada vez mais no cenário de sala de aula universitário um modelo centrado no discente, construído em compartilhamento de saberes múltiplos que interagem e integram-se, favorecendo a aquisição de conhecimento capaz de ativar, modificar e transformar a si mesmo, o outro e o meio onde se vive.

Efetivamente, pode-se afirmar que a educação, atualmente, exige que se equacione o processo pedagógico de forma diferente. No entanto, a mudança não deve ser vista só do ponto de vista tecnológico, mas sobretudo em termos de mentalidade e de prática. Essa realidade implica uma alteração cultural, pois obriga todos os envolvidos com a educação a repensar os papéis dos atores principais (docentes e discentes), e a relação existente entre eles para além das implicações no nível da planificação de cursos e currículos, sistemas de avaliação e formas de ensinar e aprender (MOREIRA; MONTEIRO, 2015).

\section{METODOLOGIAS ATIVAS, ENSINO DA NEUROANATOMIA E TECNOLOGIAS DE INFORMAÇÃO E COMUNICAÇÃO}

Estudos apontam para a necessidade atual das universidades em buscar novas metodologias de ensino, a fim de solidificar o conhecimento aprendido pelos discentes por meio de métodos ativos e significativos de aprendizagem (VASCONCELOS et al., 2019). Assim, uma nova estrutura de ensino exigirá dos docentes o desenvolvimento de uma metodologia muito mais flexível e plural, bem como uma atenção mais personalizada aos estudantes (SOUZA; CALABAIDE; ERNESTO, 2019).

Nesse sentido, emergem as metodologias ativas, caracterizadas, essencialmente, por modificar a postura discente de passivo para ativo, de modo a permitir tanto a obtenção do conhecimento quanto o desenvolvimento de habilidades e atitudes inerentes a um ser social, crítico e reflexivo. De maneira geral, pode-se dizer que as metodologias ativas buscam desenvolver o aprendizado, utilizando parâmetros reais ou simulados, construindo processos interativos de conhecimento, de análise ou de pesquisa. Desse entrelaçamento decorre a tomada de decisões individuais ou coletivas com a finalidade de encontrar soluções para um determinado problema (MARIN et al., 2010).

Desse modo, a aplicabilidade e a utilização das metodologias ativas de aprendizagem com vistas a uma aprendizagem significativa fazem-se imprescindíveis no processo de formação 
profissional, especialmente na área da saúde (MARIN et al., 2010). Especificamente quanto ao ensino da Neuroanatomia, referente ao campo de estudo da Anatomia que se dedica a reconhecer macro e microscopicamente as estruturas do sistema nervoso, assim como seu funcionamento, a necessidade de inovação acerca das metodologias de aprendizagem é pulsante. Isso se justifica por essa unidade curricular pertencer aos primeiros períodos das matrizes curriculares das graduações em saúde e destacar-se por exigir a aprendizagem de um grande número de informações (MENESES, 2015).

Um dos fatores mais agravantes quanto ao ensino da Neuroanatomia é que, ao longo dos anos, o tempo dedicado a ele tem-se reduzido paulatinamente, ao passo que essencialmente seu conteúdo seja o mesmo. Observa-se que, nos primórdios da educação médica americana, a Anatomia ocupava em torno de um quinto do currículo médico e contava com aulas teóricas tradicionais (exposição do conteúdo pelo professor e participação passiva do aluno no processo de aprendizado) e dissecação em laboratório de Anatomia macroscópica (FARIA et al., 2014).

Atualmente tentativas de novas reformas curriculares incluíram a redução das horas de laboratório e dissecação semanal e o aumento da integração entre ciência básica e clínica nos anos iniciais da formação médica, além da utilização dos avanços eletrônicos e tecnológicos disponíveis. Assim, os conteúdos são apresentados aos discentes de forma segmentada, realizada através de aulas teóricas e práticas associadas às alternativas metodológicas que auxiliam na fixação do conhecimento (FARIA et al., 2014; SILVA et al., 2017).

No entanto, pesquisas em Neuroanatomia e em campos correlatos têm sido realizadas continuamente, trazendo novos conhecimentos de modo muito rápido (MENESES, 2015), que, agregando-se aos já existentes, exigem do docente a competência e a habilidade de tornar o processo de aprendizagem interessante, agradável, e, por que não dizer: atrativa.

Somadas às bem conhecidas aulas expositivo-dialogadas e práticas, diferentes estratégias de favorecer o processo de aprendizagem têm ganhado destaque no âmbito educacional (HASHIMOTO; CIACCIO; GUERRA, 2018). No ensino específico da Neuroanatomia, a confecção de modelos morfológicos tem sido apresentada como meio alternativo na ensinagem da Neuroanatomia e vem sendo aplicada em instituições de ensino superior há algum tempo, priorizando o desenvolvimento de projetos lúdicos.

Silva et al. (2017) e Silva Junior et al. (2014a), em estudos realizados sobre o tema, constataram que a confecção de modelo funcional neuroanatômico apresenta-se como uma ferramenta alternativa de fácil manipulação que pode contribuir com o conhecimento das estruturas neuroanatômicas microscópicas e macroscópicas, já que demonstram a relação entre elas no interior do corpo humano. 
Dentro da perspectiva de inovação, Foureaux et al. (2015) apresentam a utilização dos mapas conceituais como ferramenta didática em Neuroanatomia, os quais auxiliam na compreensão dos temas relacionados a essa unidade curricular pela maioria dos alunos. Segundo esses autores, os mapas contribuem para maior satisfação do aluno em relação ao seu aprendizado e, como consequência, geram melhor rendimento individual. No entanto, eles ressaltam que, devido ao fato de a aprendizagem ser um processo individual, a metodologia pode não ser aplicável a todos.

Silva Júnior et al. (2014b) apresentam a elaboração de roteiros de aulas práticas como uma estratégia rápida, simples e eficiente, sendo esse procedimento alternativo, didático e fundamental ao processo do ensino-aprendizagem em Anatomia e Neuroanatomia. Além disso, os autores ressaltam que esse procedimento facilita o entendimento teórico-prático do aprendente.

O uso de ferramentas tecnológicas como estratégia pedagógica para a prática docente pode ser facilitado pelo uso da plataforma Google, mais especificamente o Google Forms. Essa ferramenta possibilita ao professor elaborar ações de avaliação, por meio de questionários que deverão ser respondidos com conexão à internet, colaborando para o processo de aprendizagem (JUNIOR; CASTAMAN, 2017).

Nunes (2016) propôs-se a aplicar o peer instruction ${ }^{3}$ (instrução em pares) no ensino tecnológico com auxílio do Google Forms, que consiste em um método rápido e de baixo custo, eficaz para a criação de atividades online. Nele, é possível analisar os seus resultados, uma vez que apresenta os dados em uma planilha do Microsoft Excel, proporcionando significativas modalidades de colaboração para a educação e não carecendo de nenhuma habilidade técnica especial para criar um formulário nesse espaço.

Entretanto, na sociedade atual, ter um smartphone deixou de ser exclusivo de alguns para se tornar um objeto de uso corrente, cuja propagação veio influenciar não só os hábitos cotidianos, mas também o meio profissional. Não tão difícil de adquirir-se, o smartphone chegou à escola e às universidades, não só como meio de comunicação ou entretenimento, mas como um excelente recurso pedagógico que pode potencializar o processo de ensinoaprendizagem (VIEIRA; COUTINHO, 2013).

Assim, atualmente, o aparelho representa uma alternativa, entre vários outros dispositivos, que pode ser explorada para a aprendizagem, no que é nomeado Mobile Learning

\footnotetext{
${ }^{3} \mathrm{O}$ Peer Instruction é muito utilizado como ferramenta de aprendizagem das metodologias ativas e tem por objetivo envolver os alunos em atividades cooperativas de discussão de conteúdos para efetivar a aprendizagem. Foi desenvolvido pelo físico Eric Mazur, em 1997, ensinando uma unidade física introdutória para calouros em Harvard. É considerada uma técnica simples e eficaz que permite ao professor trabalhar aulas mais interativas, envolventes e práticas (BRITO; CAMPOS, 2019, p. 377).
} 
(aprendizagem móvel). As justificativas para a apropriação do smatphone para o processo de ensino-aprendizagem seriam: a familiaridade, a mobilidade, a portabilidade e a conectividade, atributos apontados como potencializadores dessa atividade (FONSECA, 2013).

Com o smartphone é possível, por exemplo, a leitura de um $Q R$ code (quick response), que consiste em um código de identificação presente em diversos lugares, até embalagens de produtos na perspectiva educacional. A leitura desse código é feita com um aplicativo que pode ser facilmente instalado nos aparelhos que possuem câmera fotográfica (PINTO; FELCHER; FERREIRA, 2016).

Segundo as autoras supracitadas, um $Q R$ code consiste em um código de barras em 2D, cuja leitura é feita através da câmera fotográfica de dispositivos móveis que contenham um scanner para ele. Ele é capaz de incorporar informação sob a forma de URL, SMS, número de telefone, contatos e texto, além de poder ser criado por meio das ferramentas disponíveis gratuitamente na internet.

O ensino associado a essas experiências tecnológicas abre novos horizontes, perspectivando não a transmissão crua do conhecimento, mas favorecendo a descoberta, a aventura e a exploração. Diante do exposto, o professor torna-se um guia nessa nova viagem, em que os alunos criam uma relação intrínseca com o conhecimento, quebrando fronteiras, criando links entre a sala de aula e o espaço ao redor (VIEIRA; COUTINHO, 2013).

Partindo das possibilidades encontradas ao associar práticas metodológicas ativas e tecnologia, este trabalho objetivou apresentar o relato de experiência do uso do smartphone, do $Q R$ code generator e do Google Forms no favorecimento da aprendizagem acerca do tronco encefálico no ensino da Neuroanatomia.

\section{RELATO DE EXPERIÊNCIA}

\section{Contexto da sala de aula}

A unidade curricular Neuroanatomia é ofertada no segundo período do curso de Fisioterapia de uma instituição privada da Paraíba, com carga horária atual de 60h, histórico de baixo aproveitamento e baixo índice de aprovação. No entanto, há cerca de cinco anos, a unidade curricular passou por uma série de modificações. Primeiramente, a carga horária passou de $120 \mathrm{~h}$ para $60 \mathrm{~h}$, o que se apresenta como uma tendência nas instituições de ensino superior (IES) (FARIA et al., 2014) e que pode ser encarado positiva ou negativamente. No contexto da presente experiência, com a redução da carga horária, foi possível selecionar prioridades concernentes à aplicação prática de cada conteúdo e otimizar o tempo dispendido para cada um. 
Prontamente a essa medida, a capacitação constante, promovida pela IES, permitiu conhecimento teórico-prático para a inserção de práticas metodológicas ativas, a exemplo da elaboração do modelo neuroanatômico com massa de modelar, massa de biscuit ou isopor (SILVA et al., 2017; SILVA JUNIOR et al., 2014a); da apresentação de resumos referentes aos conteúdos abordados na unidade curricular; dos mapas conceituais e dos painéis integrados (FOUREAUX et al., 2015) construídos em sala de aula ou ambiente domiciliar; dos jogos neuroanatômicos (CARNEIRO et al., 2014; SOARES); da elaboração de paródias (SOARES; MOREIRA, 2018a) e da criação de mídias digitais (SOARES; MOREIRA, 2018b), cujas experiências exitosas são apresentadas na literatura científica e disponibilizadas para experienciações.

Ao longo desse tempo, tem-se investido em técnicas de ensino como problematização, team based learning (aprendizagem em equipes), peer instruction (instrução em pares), elaboração de paródias, aulas expositivo-dialogadas e teórico-práticas. Agregando valor a essas técnicas, utiliza-se ainda de tecnologias de informação e comunicação (TIC) para otimizar a ensinagem, dentre as quais se destacam na vivência prática a plataforma Moodle e a Blackboard, para disponibilização de sala virtual de aprendizagem (AVA), além do $Q R$ Code, do smartphone e das ferramentas do Google (Forms, Drive etc.).

O investimento em tecnologia e capacitação tem permitido redução significativa do número de reprovações. Anteriormente, o número de estudantes reprovados era suficiente para a abertura de uma turma adicional para alocá-los e para a necessidade de pequenos cursos nas férias. Contudo, a implantação de novas ferramentas tecnológicas e metodológicas permitiu menor número de reprovações (entre zero e duas por semestre) e melhor aproveitamento da disciplina.

Ainda assim, com o boom do uso do smartphone, que para muitos seria um vilão, para a IES é um facilitador quando bem inserido no contexto de sala de aula. Assim, de vilão, o aparelho passou a ser um importante elemento para a ensinagem da Neuroantomia, especificamente sobre o tronco encefálico, cuja experiência será detalhada a seguir.

\section{A experiência}

Para a abordagem do conteúdo, inicialmente foi solicitada a elaboração de um resumo préaula baseado em livros, textos ou sites confiáveis da internet. No dia acordado para realização da aula, foi realizada uma miniexposição dialogada com auxílio do projetor multimídia, e, ao final, foi apresentado o $Q R$ code contendo a atividade de revisão.

Para elaboração dessa atividade de revisão contida no $Q R$ code, foram seguidas três etapas. Na etapa 1: foram selecionadas imagens de atlas anatômicos, as quais foram escaneadas, e, em seguida, procedidas a edições de modo a sinalizar a estrutura anatômica que se desejava 
identificar. Foram selecionadas 20 imagens, totalizando 20 acidentes anatômicos. A sinalização foi realizada mediante inserção de uma seta em cor preta junto à estrutura anatômica de interesse.

Na etapa 2, concernente a criação do Google Forms, fez-se necessário acessar o Google Drive, que consiste em um serviço de armazenamento na nuvem, com versões para celulares Android e iPhone (iOS) e web, no computador. Com ele, é possível gerenciar arquivos; criar documentos de texto, planilhas, apresentações e formulários; fazer backup, além de enviar arquivos e fotos do celular (GOOGLE, 2019).

No item Forms do Google Drive, tem-se a opção de inserir imagem e junto a ela acrescentar texto, para um questionamento, por exemplo, e, além disso, há a possibilidade de agregar resposta curta, descritiva ou do tipo múltipla escolha. Para o presente relato, utilizou-se a opção de apresentar uma imagem, uma pergunta e uma resposta do tipo múltipla escolha contendo três opções de resposta.

Como a criação do Google Forms foi feita online através do computador, copiou-se o link da URL com o formulário contendo a revisão proposta. Com o link disponível, haveria diferentes possibilidades de compartilhamentos, mas optou-se pela geração do $Q R$ code. A razão pela qual se elegeu esse instrumento para compartilhar a atividade deveu-se ao fato de ele ser versátil, prático e suscitar curiosidade.

Para a etapa 3, que consistiu no acesso e na criação do $Q R$ code generator, foi realizado o acesso a um site de geração gratuita de $Q R$ code (https://br.qr-code-generator.com/), no qual foi inserido o link da tarefa gerada no Google Forms. Ao clicar no ícone $\langle$ Criar $Q R$ code $\rangle$ obtém-se, no canto direito da tela, o código pronto para ser baixado para o computador e utilizado pelo docente. Esse código havia sido impresso em uma folha de papel A4 e fixado nas laterais da sala de aula para captação com o smartphone e resposta individual.

Para finalizar a aula, após a captação do $Q R$ code pelos smartphones e a realização dos preenchimentos individuais, a atividade deveria ser finalizada com o clique em <Enviar formulário>. Simultaneamente, o docente, conectado à rede Wi-fi da IES e com o Drive aberto, atualizava as respostas dadas pelos discentes.

No Drive é alimentada uma planilha do Excel com os resultados da tarefa. Sendo assim é possível gerar um conjunto de gráficos contendo a frequência das respostas em porcentagem. Com essas informações em mãos e de forma instantânea, torna-se fácil e rápida a identificação das principais fragilidades quanto à fixação do conteúdo abordado. Dessa maneira, em tempo hábil o docente juntamente com os discentes pode criar uma rede de colaboração com objetivo de dirimir as dúvidas residuais, garantindo assim a aprendizagem. 


\section{DISCUSSÃO}

Segundo Bastos, Rapkiewicz e Benvenuti (2016), a possibilidade de aprender utilizando novas tecnologias, de modo a gerar maior comunicação assim como compartilhamento de conteúdo em tempo real a longas distâncias, é uma importante ferramenta de integração. Em seu estudo, a proposta era de integrar os componentes curriculares de Língua Portuguesa e Cultura Digital, e, quanto ao seu objetivo, as autoras ressaltam que o uso do $Q R$ code associado ao smartphone foi capaz de estimular o bom uso do celular e promover a inclusão digital discente.

Moreira e Monteiro (2015) relatam que a utilização do $Q R$ code permite a agregação de inúmeras possibilidades, a exemplo da URL, do VCard, do texto, do e-mail, do SMS, das redes sociais, dos arquivos em pdf, dos áudios em $\mathrm{mp} 3$, dos app stories e das imagens. A utilização dessa ferramenta pode ser de modo gratuito, que permite o uso e o tempo limitado de recursos, ou pago, que é mais amplo.

Nichele, Schlemmer e Ramos (2015) ressaltam a crescente adoção de dispositivos móveis, como smartphones e tablets, entre os estudantes e os professores como potencial ferramenta inovadora dos processos de ensino e de aprendizagem, em especial no que se relaciona à ação e à interação dos sujeitos, bem como à forma de produzir, acessar e compartilhar a informação no contexto da mobilidade. As autoras reforçam que a experiência com os $Q R$ codes associados a vídeos confirmou o uso dessa ferramenta como uma estratégia facilitadora para o processo de aprendizagem.

Pinto, Felcher e Ferreira (2016), acerca do uso do $Q R$ code e do smartphone, compartilharam que se tratou de uma experiência positiva, no sentido do empenho dos discentes na realização da atividade proposta, tornando-a muito relevante no ambiente de sala de aula. Ao mesmo tempo, verificou-se grande facilidade em lidar com a tecnologia, que indica desdobramentos animadores quanto à forma de apresentar e orientar a solução dos desafios na disciplina de Matemática, na qual a atividade foi proposta.

Diante do exposto, identificam-se muitas vantagens no uso dessas tecnologias: aproveitamento do smartphone a favor da construção do conhecimento, favorecimento da comunicação e da integração docente-discente de maneira colaborativa e aprovação da metodologia de ensino pelos aprendentes, considerada como mais atrativa e eficiente para o docente, já que é possível identificar as fragilidades e saná-las ainda em sala de aula. Como desvantagem, pode-se referenciar o fato de que, mesmo sendo um aparelho comum, nem todos os discentes possuem-no. Por outro lado, esse obstáculo tem sido vencido pelo "empréstimo" pelos colegas que já finalizaram a tarefa. Outra dificuldade é a rede de Wi-fi que, a depender do espaço onde se está trabalhando, acaba sendo uma limitação importante. 
Luciana Maria de Morais Martins Soares, Rodrigo Farias Herculano Mendes

Monteiro e Moreira (2015) alertam que, apesar das vantagens que representam, essas tecnologias demandam uma quase permanente formação, porque nessa área a inovação acontece a todo momento, o que, por vezes, proporciona mudanças significativas nas práticas dos professores. Além disso, faz-se necessário o conhecimento de softwares, a identificação dos reais objetivos e a sua utilização do ponto de vista pedagógico. Além disso, é fundamental identificar se o recurso é o mais adequado para o efeito esperado.

Assim, sugere-se a oferta de momentos de formação que garantam não só a aquisição de competências na manipulação dessas ferramentas, mas também o fomento da reflexão sobre suas potencialidades. Nesse contexto, o presente trabalho foi facilitado devido ao fato de, há muitos anos, a instituição e a gestão estarem preocupadas e engajadas na aplicação de novas tecnologias, o que facilita sua inserção dentro do contexto geral.

Ribas et al. (2017) reforçam que, apesar de a utilização da tecnologia como recurso pedagógico estar tornando-se uma prática cada vez mais comum por parte dos educadores, ainda existe uma dificuldade no processo de implementação, em particular do $Q R$ code. Isso ocorre uma vez que o ambiente em que se educa precisa estar apto a acolher a tecnologia como aliada no processo educacional, compreendendo que ela está cada vez mais presente na sociedade atual. Nesse ínterim, mesmo que o ambiente educacional e os profissionais tornem-se aptos a utilizar esse recurso, ainda há o desafio de propiciar o acesso para todos os alunos. Embora a tecnologia esteja presente, não são todos os alunos que possuem acessibilidade aos recursos tecnológicos.

\section{CONSIDERAÇÕES FINAIS}

O presente relato objetivou apresentar a associação do smartphone com o $Q R$ code no suporte ao ensino da Neuronatomia. Diante do cenário atual de inovação tecnológica no plano educacional e da mudança frequente do perfil dos discentes nos bancos universitários, a utilização de tecnologias e a reflexão acerca do seu uso justifica-se de modo a prover subsídios teóricos que suportem sua implementação prática em sala de aula.

Verificou-se que a utilização dessas ferramentas em associação e a favor do processo de aprendizagem trouxe muitas vantagens: aproveitamento do smartphone na construção do conhecimento; melhoria da comunicação e da integração docente-discente de maneira colaborativa, além da percepção discente como metodologia mais atrativa e eficiente, no sentido de permitir a identificação dos problemas e a sua solução durante a aula.

Entretanto, como desvantagem, no sentido de implementação em outras realidades, podese mencionar que, apesar de ser um aparelho comum, nem todos os discentes possuem o smartphone, podendo, a depender da estratégia do docente, constituir uma grande limitação. Para essas situações, sugere-se o trabalho em pares ou em equipes. Além disso, a 
depender da IES e da rede de Wi-fi, a efetividade da atividade poderá ser reduzida devido ao feedback em sala de aula, o que pode, no entanto, ser contornado com a realização da atividade a posteriori, em outro encontro em sala de aula, por exemplo.

Mesmo sendo prática e de fácil utilização, a implantação de tecnologias em sala de aula exige capacitação constante dos facilitadores/docentes, tendo em vista a renovação contínua dessas ferramentas, a abertura e a solidificação de condições físicas (estruturais) e mentais (conceitual-filosóficas) para sua aceitação, a aplicação prática e a reflexão do uso nas salas de aula dos bancos universitários.

\section{REFERÊNCIAS}

ALTHAUS, Maiza Taques Margraf; BAGIO, Viviane Aparecida. As metodologias ativas e as aproximações entre o ensino e a aprendizagem na prática pedagógica universitária. Revista Docência do Ensino Superior, Belo Horizonte, v. 7, n. 2, p. 79-96, jul./dez. 2017. DOI: https://doi.org/10.35699/2237-5864.2017.2342. Disponível em: https://periodicos.ufmg.br/index.php/rdes/article/view/2342 . Acesso em: 22 jan. 2019.

BASTOS, Deise Luana Rosa; RAPKIEWICZ, Clevi; BENVENUTI, Juçara. Integrando $Q R$ code na educação na EJA: um projeto-piloto voltado para entendimento da língua portuguesa. In: CONGRESSO BRASILEIRO DE INFORMÁTICA NA EDUCAÇÃO, 5., 2016. Uberlândia. Anais [...] Uberlândia: Sem editora, 2016. p. 221. Disponível em: http://www.brie.org/pub/index.php/wie/article/view/6640. Acesso em: 29 jan. 2019.

BRITO, Carlos Alexandre Felício; CAMPOS, Marcia Zendron. Facilitando o processo de aprendizagem no ensino superior: o papel das metodologias ativas. Revista Ibero-Americana de Estudos em Educação, Araraquara, v. 14, n. 2, p. 371-387, jan. 2019. DOI: https://doi.org/10.21723/riaee.v14i2.11769.

CARNEIRO, Miriam Lucia Nóbrega et al. Uso de metodologias ativas no processo de ensino e aprendizagem em Neuroanatomia. Cadernos de Educação, Saúde e Fisioterapia, Campo Grande, v. 1, n. 1, p. 261. 2014. Disponível em: http://revista.redeunida.org.br/ojs/index.php/cadernos-educacao-saudefisioter/article/view/261. Acesso em: 22 de jan. 2019.

CORTELA, Beatriz S. C. Práticas inovadoras no ensino de graduação na perspectiva de professores universitários. Revista Docência do Ensino Superior, Belo Horizonte, v. 6, n. 2, p. 9-34, jul./dez. 2016. DOI: https://doi.org/10.35699/2237-5864.2016.2114. Disponível em: https://seer.ufmg.br/index.php/rdes/article/view/1410. Acesso em: 22 jan. 2019.

FARIA, José Weber Vieira et al. A evolução histórica do ensino da Neuroanatomia. Revista de Medicina, São Paulo, v. 93, n. 4, p. 146-150, out./dez. 2014. DOI:

http://dx.doi.org/10.11606/issn.1679-9836.v93i4p146-50. Disponível em: 
Luciana Maria de Morais Martins Soares, Rodrigo Farias Herculano Mendes

https://www.revistas.usp.br/revistadc/article/view/103584/102044. Acesso em: 29 jan. 2019.

FONSECA, Ana Graciela Mendes Fernandes. Aprendizagem, mobilidade e convergência: mobile learning com celulares e smartphones. Revista Mídia e Cotidiano, Niterói, v. 2, n. 2, p. 163-181, jun. 2013. Disponível em:

http://periodicos.uff.br/midiaecotidiano/article/view/9685. Acesso em: 29 jan. 2019.

FOUREAUX, Giselle et al. Mapas conceituais: uma valiosa ferramenta didática para o ensino da disciplina de Neuroanatomia Humana. Revista Espacios, Caracas, v. 36, n. 14, p. E-2, 2015. Disponível em: http://www.revistaespacios.com/a15v36n14/153614E3.html. Acesso em: 29 jan. 2019.

GOOGLE. Google drive. Disponível em: https://www.google.com/intl/pt-BR_ALL/drive/. Acesso em: 29 jan. 2019.

HASHIMOTO, Priscilla Cerullo; CIACCIO, Maria Cristina de Mello; GUERRA, Grazia Maria. A tendência do papel do professor no processo de aprendizagem. Nursing, São Paulo, v. 21, n. 242, p. 2264-2271, jul. 2018. Disponível em: http://www.revistanursing.com.br/revistas/242Julho2018/A_tendencia_papel_professor.pdf. Acesso em: 12 jan. 2019.

$\mathrm{JO}$, Jaechoon et al. An integrated teaching and learning assistance system meeting requirements for smart education. Wireless personal communications, v. 79, n. 4, p. 24532467, dez. 2014. DOI: https://doi.org/10.1007/s11277-014-1765-4. Disponível em: https://link.springer.com/article/10.1007/s11277-014-1765-4. Acesso em: 11 fev. 2018.

JÚNIOR, Mario Luiz Junges; CASTAMAN, Ana Sara. Tecnologias na educação: um relato de experiência na pós-graduação em teorias e metodologias da educação. Redin-Revista Educacional Interdisciplinar, Taquara, v. 6, n. 1, p. 1-11, out. 2017. Disponível em: http://seer.faccat.br/index.php/redin/article/view/646. Acesso em: 29 jan. 2019.

MARIN, Maria José Sanches et al. Aspectos das fortalezas e fragilidades no uso das metodologias ativas de aprendizagem. Revista Brasileira de Educação Médica, Rio de Janeiro, v. 34, n. 1, p. 13-20, jan./mar. 2010. DOI: http://dx.doi.org/10.1590/S010055022010000100003. Disponível em: http://www.scielo.br/scielo.php?script=sci_arttext\&pid=S010055022010000100003\&lng=en\&nrm=iso. Acesso em: 16 jun. 2019.

MENESES, Murilo S. Neuroanatomia aplicada. 3 ed. Rio de Janeiro: Guanabara Koogan, 2015. MOREIRA, José António; MONTEIRO, Angélica Maria Reis. Formação e ferramentas colaborativas para a docência na web social. Revista Diálogo Educacional, Curitiba, v. 15, n. 45, p. 379-397, jul. 2015. DOI: http://dx.doi.org/10.7213/dialogo.educ.15.045.DS01. Disponível em: 
https://periodicos.pucpr.br/index.php/dialogoeducacional/article/view/1891/1792 . Acesso em: 29 jan. 2019.

NARDI, Roberto; BASTOS, Fernando; TERRAZZAN, Eeuardo Adolfo apud CORTELA, Beatriz S. C. Práticas pedagógicas e processos formativos de professores na área de ciências e matemática. (Relatório de pesquisa referente a projeto financiado pelo Conselho Nacional de Desenvolvimento Científico e Tecnológico - CNPq). Bauru: UNESP, 2008.

NICHELE, Aline Grunewald; SCHLEMMER, Eliane; RAMOS, Adriana de Farias. $Q R$ codes na educação em Química. RENOTE, Porto Alegre, v. 13, n. 2, p. 1-9, dez. 2015. DOI: https://doi.org/10.22456/1679-1916.61425. Disponível em: https://seer.ufrgs.br/renote/article/view/61425. Acesso em: 29 jan. 2019.

NÖRNBERG, Nara Eunice; FORSTER, Mari Margarete dos Santos. Ensino Superior: as competências docentes para ensinar no mundo contemporâneo. Revista Docência do Ensino Superior, Belo Horizonte, v. 6, n. 1, p. 187-210, jan./jun. 2016. DOI: https://doi.org/10.35699/2237-5864.2016.2095. Disponível em: https://periodicos.ufmg.br/index.php/rdes/article/view/2095. Acesso em: 22 jan. 2019.

NUNES, Fabiano de L. Aplicação do peer instruction no ensino tecnológico superior com o auxílio do google forms: um estudo de caso. In: SIMPÓSIO DE ENGENHARIA DE PRODUÇÃO, 23., 2016. Bauru. Anais [...] Bauru: Gestão de operações em serviços e seus impactos sociais, 2016. Disponível

em: https://www.researchgate.net/profile/Fabiano_Nunes2/publication/311616431_Aplicac ao_do_Peer_Instruction_no_ensino_tecnologico_superior_com_o_auxilio_do_Google_Form s_um_estudo_de_caso/links/58513b4e08ae95fd8e1554c4.pdf. Acesso em: 29 jan. 2019.

PINTO, Ana Cristina Medina; FELCHER, Carla Denize Ott; FERREIRA, André Luis Andrejew. Considerações sobre o uso do aplicativo $Q R$ code no ensino da Matemática: reflexões sobre o papel do professor. In: ENCONTRO NACIONAL DE EDUCAÇÃO MATEMÁTICA, 12., 2016. São Paulo. Anais [...] São Paulo: SBEM, 2016. Disponível em: http://www.sbem.com.br/enem2016/anais/pdf/8323_4386_ID.pdf. Acesso em: 29 jan. 2019.

RIBAS, Ana Carolina et al. O uso do aplicativo $Q R$ code como recurso pedagógico no processo de ensino e aprendizagem. Ensaios Pedagógicos, Sorocaba, v. 7, n. 2, p. 12-21, jul./dez. 2017. Disponível em: http://www.opet.com.br/faculdade/revista-pedagogia/pdf/n14/n14-artigo2-O-USO-DO-APLICATIVO-QR-CODE.pdf. Acesso em: 29 jan. 2019.

RODRÍGUEZ, Miguel Navarro. Proceso de autorregulación del aprendizaje en el e-portafolio: narrativas digitales de estudiantes de doctorado de la Universidad Pedagógica de Durango. 3 c TIC: cuadernos de desarrollo aplicados a las TIC, Alcoy, v. 3, n. 4, p. 240-269, mar./jun. 2014. DOI: https://doi.org/10.17993/3ctic.2014.34.240\%20-\%20269. Disponível em: https://dialnet.unirioja.es/servlet/articulo?codigo=4903919. Acesso em: 11 fev. 2018. 
SILVA JÚNIOR, Ednaldo Xavier et al. Elaboração de modelos anatômicos alternativos para o ensino-aprendizagem da disciplina de Neuroanatomia Humana, a partir de material de baixo custo. In: CONGRESSO NACIONAL DE EDUCAÇÃO, 1., 2014, Campina Grande. Anais [...] Campina Grande: Realize, 2014a. Disponível em: http://www.editorarealize.com.br/revistas/conedu/trabalhos/Modalidade_1datahora_ 14_07_2014_19_51_54_idinscrito_3160_eec18973fabcaf6b30f5b526540557cc.pdf. Acesso em: 29 jan. 2019.

SILVA JÚNIOR, Ednaldo Xavier et al. Elaboração de roteiros para o ensino-aprendizagem nas aulas práticas das disciplinas de Anatomia Humana e Neuroanatomia. In: CONGRESSO NACIONAL DE EDUCAÇÃO, 1., 2014. Campina Grande. Anais [...] Campina Grande: Realize, 2014b. Disponível

em: http://www.editorarealize.com.br/revistas/conedu/trabalhos/Modalidade_1datahora_ 15_07_2014_22_59_18_idinscrito_3160_6ad18d13d81622ec0227b39630b0b40a.pdf. Acesso em: 29 jan. 2019.

SILVA, Yslaíny Araújo et al. Confecção de modelo neuroanatômico funcional como alternativa de ensino e aprendizagem para a disciplina de Neuroanatomia. Revista IberoAmericana de Estudos em Educação, Araraquara, v. 12, n. 3, p. 1674-1688, jul./set. 2017. DOI: http://dx.doi.org/10.21723/riaee.v12.n.3.2017.8502. Disponível em: https://periodicos.fclar.unesp.br/iberoamericana/article/view/8502. Acesso em: 29 jan. 2019.

SOARES, Luciana Maria de Morais Martins; MOREIRA, lara Fialho. A música como ferramenta pedagógica no aprendizado em Neuroanatomia. In: SAPIENS, 5., 2016. João Pessoa. Caderno de Resumos da V Sapiens. João Pessoa: UNIPÊ, 2018a, p. 29. Disponível em: https://unipe.edu.br/books/produto/caderno-de-resumos-da-v-sapiens-2016/. Acesso em: 22 jan. 2019.

SOARES, Luciana Maria de Morais Martins; MOREIRA, lara Fialho. A elaboração de mídia digital como ferramenta de aprendizagem da Neuroanatomia. In: SAPIENS, 5., 2016, João Pessoa. Caderno de Resumos da V Sapiens. João Pessoa: UNIPÊ, 2018b, p. 37. Disponível em: https://unipe.edu.br/books/produto/caderno-de-resumos-da-v-sapiens-2016/. Acesso em: 22 jan. 2019.

SOUZA, Carlos Henrique Medeiros; CALABAIDE, Cecília; ERNESTO, Talita Silva. Reflexões sobre metodologias ativas $x$ prática docente. LINKSCIENCEPLACE-Interdisciplinary Scientific Journal, São Carlos, v. 5, n. 4, p. 212-222, out./dez. 2019. DOI: http://dx.doi.org/10.17115/2358-8411/v5n4a15. Disponível em: http://revista.srvroot.com/linkscienceplace/index.php/linkscienceplace/article/view/582. Acesso em: 16 jun. 2019.

VASCONCELOS, Andreza Cavalcanti et al. As estratégias de ensino por meio das metodologias ativas. Brazilian Journal of Development, São José dos Pinhais, v. 5, n. 5, p. 3945-3952, abr. 2019. Disponível em: 
http://www.brazilianjournals.com/index.php/BRJD/article/view/1568. Acesso em: 16 jun. 2019.

VIEIRA, Liliana de Sousa; COUTINHO, Clara Pereira. Mobile learning: perspetivando o potencial dos códigos QR na educação. In: VIII CONFERÊNCIA INTERNACIONAL DE TIC NA EDUCAÇÃO - CHALLENGES 2013, 8., 2013. Atas [...] Braga: Universidade do Minho. Centro de Competência do Projecto Nónio Século XXI, 2013. p. 73-91. Disponível em: https://repositorium.sdum.uminho.pt/handle/1822/25450. Acesso em: 29 jan. 2019.

\section{Luciana Maria de Morais Martins Soares}

Doutora e mestre em Evolução Humana: antropologia física e forense (Universidad de Granada, Espanha), especialista em Fisioterapia Neurofuncional (Associação Brasileira de Fisioterapia Neurofuncional - ABRAFIN) e em Gerontologia (Faculdades Integradas de Patos - FIP). Fisioterapeuta (Universidade Federal da Paraíba - UFPB). Professora e pesquisadora do Centro Universitário de João Pessoa (UNIPE). Temáticas: fisioterapia neurogerontológica, psicomotricidade, pilates, metodologias ativas no ensino superior.

luciana_momaso@hotmail.com

\section{Rodrigo Farias Herculano Mendes}

Mestrando em Ciência e Tecnologia em Saúde (Universidade Estadual da Paraíba - UEPB), especialista em Sistemas e Computação e Matemática Aplicada (Universidade Federal do Rio Grande do Norte) e em Metodologias Ativas de Aprendizagem (Centro Educacional de Ensino Superior de Patos - CEPESP), analista de Sistemas da Informação (Faculdades Integradas de Patos - FIP). Professor do Centro Educacional de Ensino Superior de Patos (CEPESP) e membro do Núcleo de Ensino a Distância. Temáticas: algoritmo, inclusão digital e social, scratch, ensino a distância, metodologias ativas no ensino superior.

rodrigofhmendes@gmail.com 